\section{A) Check for updates}

Cite this: Polym. Chem., 2021, 12 5505

Received 15th June 2021

Accepted 7th September 2021

DOI: $10.1039 / \mathrm{d} 1 \mathrm{py} 00801 \mathrm{c}$

rsc.li/polymers

\title{
Direct synthesis via RAFT of amphiphilic diblock polyelectrolytes facilitated by the use of a polymerizable ionic liquid as a monomer $\uparrow$
}

\begin{abstract}
Aleksander Guzik (D) ${ }^{a, b}$ and Patrizio Raffa (DD*a
A new method for obtaining amphiphilic block polyelectrolytes with a strongly hydrophobic block under homogeneous conditions is described and demonstrated by synthesizing poly(2-acrylamido-2-methanepropanesulfonate- $b$-styrene) block copolymers using RAFT polymerization. The technique involves the transformation of the 2-acrylamido-2-methanepropanesulfonate (AMPS) monomer into a polymerizable ionic liquid (PIL) by neutralization with triethylamine, which renders the resulting $\mathrm{P}\left(\mathrm{Et}_{3} \mathrm{~N}-\mathrm{AMPS}\right)$ macroCTA soluble in DMF, DMSO, and ethanol. Consequently, straightforward homogeneous chain extension with a strongly hydrophobic monomer such as styrene is possible under homogeneous conditions. Homopolymerization of the PIL monomer is studied, revealing pseudo- $1^{\text {st }}$-order kinetics and polydispersities slightly higher than those for the Na-AMPS monomer. High end group fidelity is demonstrated by chain extension experiments. Amphiphilic diblock copolymers are synthesized in a range of targeted chain compositions, and their formation is confirmed by SEC and ${ }^{1} \mathrm{H}$-DOSY, and by investigating selfassembled structures with DLS. The reverse approach based on styrene-first polymerization also proved successful, further expanding the scope of this work. We believe that this provides an interesting alternative to protection-deprotection methods and emulsion polymerization methods, when strongly anionic block copolymers are desired.
\end{abstract}

\section{Introduction}

Strong polyelectrolytes are well-established polymeric materials. Compared to weak ones, they may present some advantages, depending on the intended application, such as $\mathrm{pH}$-independent ionization, solution stability in the presence of divalent cations, and strong interactions between chains. 2-Acrylamido-2-methylpropanesulfonic acid (AMPS) is a sulfonate-bearing monomer that can be used as an alternative for styrene sulfonate to introduce strong ionic groups into a copolymer, affording strong polyelectrolytes. AMPS has a fast rate of propagation and is hydrolytically stable. For these reasons, AMPS has been applied in biomaterials, ${ }^{1}$ hydrogels, ${ }^{2}$ colloid stabilizers, ${ }^{3,4}$ solid electrolytes for fuel cells, ${ }^{5}$ and polymers for enhanced oil recovery. ${ }^{6-8}$

These applications can be potentially greatly expanded by producing AMPS-containing well-defined block copolymers.

\footnotetext{
${ }^{a}$ Department of Chemical Engineering - Product Technology, ENTEG Institute, Faculty of Science and Engineering, University of Groningen, Nijenborgh 4, 9747 AG Groningen, The Netherlands. E-mail: p.raffa@rug.nl

${ }^{b}$ DPI, P.O. Box 902, 5600 AX Eindhoven, The Netherlands

$\dagger$ Electronic supplementary information (ESI) available: Additional ${ }^{1} \mathrm{H}-\mathrm{NMR}$ spectra, UV-VIS, elemental analysis results, SEC traces, DOSY results and additional DLS information. See DOI: 10.1039/d1py00801c
}

Such materials are generally easily made using a range of controlled radical polymerization methods (CRP), ${ }^{9}$ one of which is reversible addition-fragmentation transfer polymerization (RAFT). ${ }^{10}$ RAFT is based on the presence of a chain transfer agent (CTA), typically in the form of a dithiobenzoate, trithiocarbonate or a xanthate, in a radical polymerization mixture. It is easy to conduct and set up, and it allows tailoring both the polymer composition and, in a recent development, also its polydispersity. ${ }^{11}$

AMPS (as well as other similar strongly anionic sulfonate monomers) has been polymerized using controlled radical polymerization methods, either on its own to form the corresponding homopolymer ${ }^{12}$ or co-polymerized with other monomers such as: $N, N$-dimethylacrylamide, ${ }^{13}$ 2-hydroxyethyl methacrylate, ${ }^{14} \mathrm{~N}$-hydroxyethyl acrylamide and 4-acryloylmorpholine ${ }^{15} \quad N$-isopropylacrylamide ${ }^{16-18} \quad 3$-acrylamido-3-methylbutanoate ${ }^{12}$ and methyl methacrylate, ${ }^{19}$ yielding either block or statistical copolymers. However, the co-polymerization of AMPS with strongly hydrophobic monomers to produce amphiphilic block copolymers is more challenging. Choosing a solvent poses a serious problem, as the commonly applied sodium salt of AMPS produces a polymer that tends to be insoluble in non-aqueous solvents. P(Na-AMPS-block-n-butyl acrylate) was synthesized using homogeneous RAFT, by dis- 
solving the acid form of AMPS in NMP. ${ }^{20}$ However, NMP is known to be toxic and difficult to remove from the product and its use should be limited. Moreover, the attained conversions were low (17-53\%), which is undesirable, especially when large molecular weights are required. Analogous block copolymers were synthesized in DMSO, but the targeted molecular weight was low, leading to less than 10 units of AMPS in the product. $^{21}$ Moreover, the use of the acid form of AMPS results in extremely low $\mathrm{pH}$ values which, even though acidic RAFT can be carried out successfully, ${ }^{22}$ may cause solubility problems $^{23}$ and may not be tolerated by other components of the reaction mixture. Additionally, many SEC columns cannot operate in strongly acidic environments, which imposes a requirement of chemical modification of every aliquot, if the evolution of $M_{\mathrm{n}}$ is to be tracked with SEC.

One common workaround is the use of protected, less polar, versions of the hydrophilic monomer. For example, polyelectrolyte block copolymers based on acrylic acid are often obtained by the polymerization of a corresponding ester, followed by a post-polymerization process of ester hydrolysis. ${ }^{24-26}$ Strongly ionic amphiphilic block copolymers can be synthesized in a similar manner, by following protection-deprotection chemistry, an example being the polymerization of vinyl sulfonates. ${ }^{27}$ Notably, such a method has been recently developed for 3-sulfopropyl methacrylate, to make P(Na-SPMAblock-styrene) copolymers. ${ }^{28}$ Even though this process gives good yield and is suitable for producing multiple grams of products, it is time-consuming and calls for dangerous chemicals, such as thionyl chloride or oxalyl chloride.

Another approach can be based on heterogeneous methods. P(Na-AMPS- $b$-styrene) has been produced by RAFTmediated Polymerization-Induced Self-Assembly (PISA), which is a variant of emulsion polymerization, whereby the macroRAFT agent is also the surfactant. ${ }^{29}$ This approach, however, is not as straightforward as bulk polymerization, as the design of the composition has to take into account mass transfer between the two phases (e.g. radical entry). It is likely that higher molecular weight macroCTAs cannot be used for chain extensions because of increased viscosity. Finally, the order of monomer addition is fixed by the requirement of water solubility of the first block, serving as the surfactant. In our opinion, the PISA method is best suited for in situ synthesis of diblock copolymer nano-objects, which are never meant to be isolated from the latex. ${ }^{30-32}$ We propose here another approach based on polymerizable ionic liquids, which allows us to overcome the mentioned limitations.

Polymerizable ionic liquids (PILs) are a subset of organic ionic liquids that contain vinyl functionalities, allowing them to undergo free radical polymerization. ${ }^{33}$ They are generally constituted by ionic groups neutralized by some bulky organic counterions that favor them to remain dissociated and in liquid form at room temperature by hindering the formation of a strong ordered lattice. AMPS-based PILs are reported in the literature as precursors for functional materials obtained by free radical polymerization. The AMPS monomer has been previously transformed into a polymerizable ionic liquid by neutralization with triethylamine. The resultant monomer has been copolymerized with styrene ${ }^{34}$ and with acrylamide to yield superabsorbent gels. ${ }^{35}$ Copolymer gels were also attained by polymerization of AMPS neutralized with butylamine or 2(N,N-dimethylamino)ethyl methacrylate. ${ }^{36}$ The 1-methylimidazole-AMPS monomer has been co-polymerized with styrene, yielding a material for proton exchange membranes. ${ }^{37}$ Other imidazole derivatives have also been used to produce protein-adsorbing polymers from AMPS. ${ }^{38}$ Surface-active polymers were made by using a surfactant amine (cetyltrimethylammonium hydroxide). ${ }^{39}$ AMPS has been polymerized and then the chains have been neutralized by tetrabutylammonium hydroxide to allow the polymer chains to be studied in a range of organic solvents. ${ }^{40,41}$ Although PILs have been polymerized with CRP, also to make block copolymers, ${ }^{42-44}$ we are not aware of any attempts to attain control of the polymerization of AMPS-based PIL by means of CRP, nor to utilize this approach to access strongly ionic non-PIL polyelectrolytes, which could be used as, e.g., water viscosifiers.

In this work we investigated the possibility of the synthesis of strongly charged amphiphilic Na-AMPS-block-styrene block copolymers according to the reaction sequence shown in Scheme 1. Neutralization of AMPS with triethylamine leads to an organic-soluble ( $\mathrm{Et}_{3} \mathrm{~N}$-AMPS)-RAFT macroCTA, which can be chain extended with the hydrophobic monomer styrene in a homogenous mixture.

\section{Experimental}

\section{Materials}

Styrene (S, Sigma-Aldrich, $\geq 99 \%$ ) was passed through a basic alumina column to remove the inhibitor and was purged with argon before use. 4,4'-Azobis(4-cyanovaleric acid) (ACVA, SigmaAldrich, $\geq 98 \%$ ) and 2,2'-azobis(2-methylpropionitrile) (AIBN, Sigma-Aldrich, 98\%) were recrystallized from methanol prior to use. 2-Acrylamido-2 methylpropanesulfonic acid (AMPS, SigmaAldrich, 99\%), triethylamine $\left(\mathrm{Et}_{3} \mathrm{~N}\right.$, Sigma-Aldrich, $\left.\geq 99 \%\right)$ and 4-((((2-carboxyethyl)thio)carbonothioyl)thio)-4 cyanopentanoic acid (CVPTTC, Boron Molecular, 98\%) were used as-received, without further purification. Water used for the reactions was obtained from a Merck Milli-Q filtration system. Synthesis of BDMAT $^{29}$ and MCEBTTC ${ }^{45}$ RAFT agents was performed according to the literature reports. Synthesis of polystyrene-RAFT macroCTA is also described elsewhere. ${ }^{46}$ Structures of RAFT agents and RAFT macroCTAs are reported in Scheme 2.

\section{Nuclear magnetic resonance}

${ }^{1} \mathrm{H}$ NMR data for the kinetic study in Fig. 1A were recorded in $\mathrm{D}_{2} \mathrm{O}$ on a $500 \mathrm{MHz}$ Varian Inova. NMR spectra in Fig. 3C were recorded in d6-DMSO on a $600 \mathrm{MHz}$ Bruker Avance NEO. All remaining NMR measurements were performed on a $400 \mathrm{MHz}$ Varian Mercury Plus, using d6-DMSO. ${ }^{1} \mathrm{H}$ DOSY experiments were carried out on a $600 \mathrm{MHz}$ Bruker Avance NEO, using the bPGSTE pulse sequence. The raw data were processed using options available in the Mnova package. The PAMPS degree of polymerization was calculated based on the ratio of integrals 

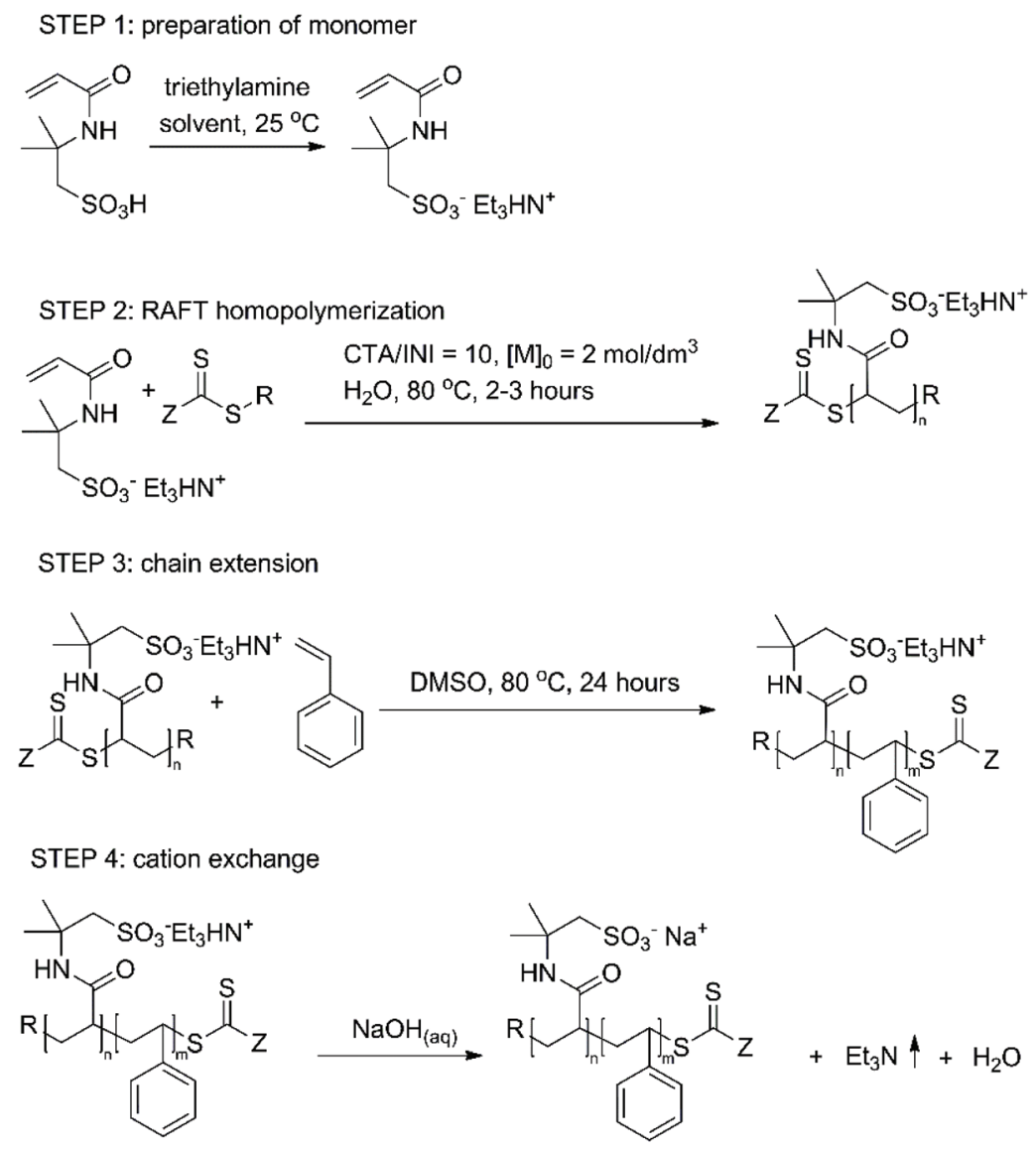

Scheme 1 Reaction sequence leading to the amphiphilic diblock polyelectrolytes studied in this work.

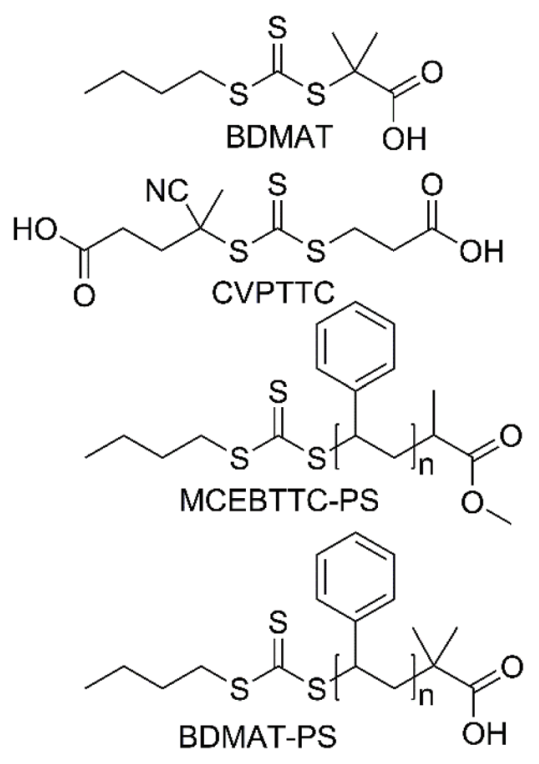

Scheme 2 Structures of RAFT agents used in this research.

of $\sigma 1.41(6 \mathrm{H})$ singlet (AMPS methyl groups) to $\sigma 2.45(2 \mathrm{H})$ and $\sigma 2.73(2 \mathrm{H})$ multiplets ( $-\mathrm{CH}_{2}-\mathrm{CH}_{2}-$ from polymer end groups). Monomer conversions for the kinetic studies were determined by relating the integral of vinyl protons to the integral of the $\sigma$ 1.41 signal.

\section{UV-VIS}

A Thermo Spectronic Aquamate UV-VIS spectrophotometer was used for all measurements. The samples were measured in glass cuvettes, immediately after preparation. The concentration of the samples was adjusted so that the signal was within the limits of the instrument.

\section{Gel permeation chromatography}

The GPC traces of DMF solutions reported in Fig. 1, Fig. S11 and $\mathrm{S} 12 \uparrow$ were measured on a Viscotek GPCmax equipped with model 302 TDA detectors, with two columns (Agilent Technologies-PolarGel-L and $\mathrm{M}, 8 \mu \mathrm{m}, 30 \mathrm{~cm}$ ) at a flow rate of $1.0 \mathrm{ml} \mathrm{min}{ }^{-1}$ and at a temperature of $50^{\circ} \mathrm{C}$. The eluent was a $10 \mathrm{mM}$ solution of $\mathrm{LiBr}$ in DMF. The system was calibrated using PMMA standards.

The chromatograms in Fig. S12† were deconvoluted by fitting a lognormal distribution using Fityk software. ${ }^{47}$

The GPC traces and values for DMF solutions reported in Table 2 and Fig. 3 were measured on an Agilent 1200 Series system, equipped with an Agilent 1200 RI detector, and a $3 \times$ PSS Gram Analytical Linear column (particle size: $10 \mu \mathrm{m} ; 8 \times$ 

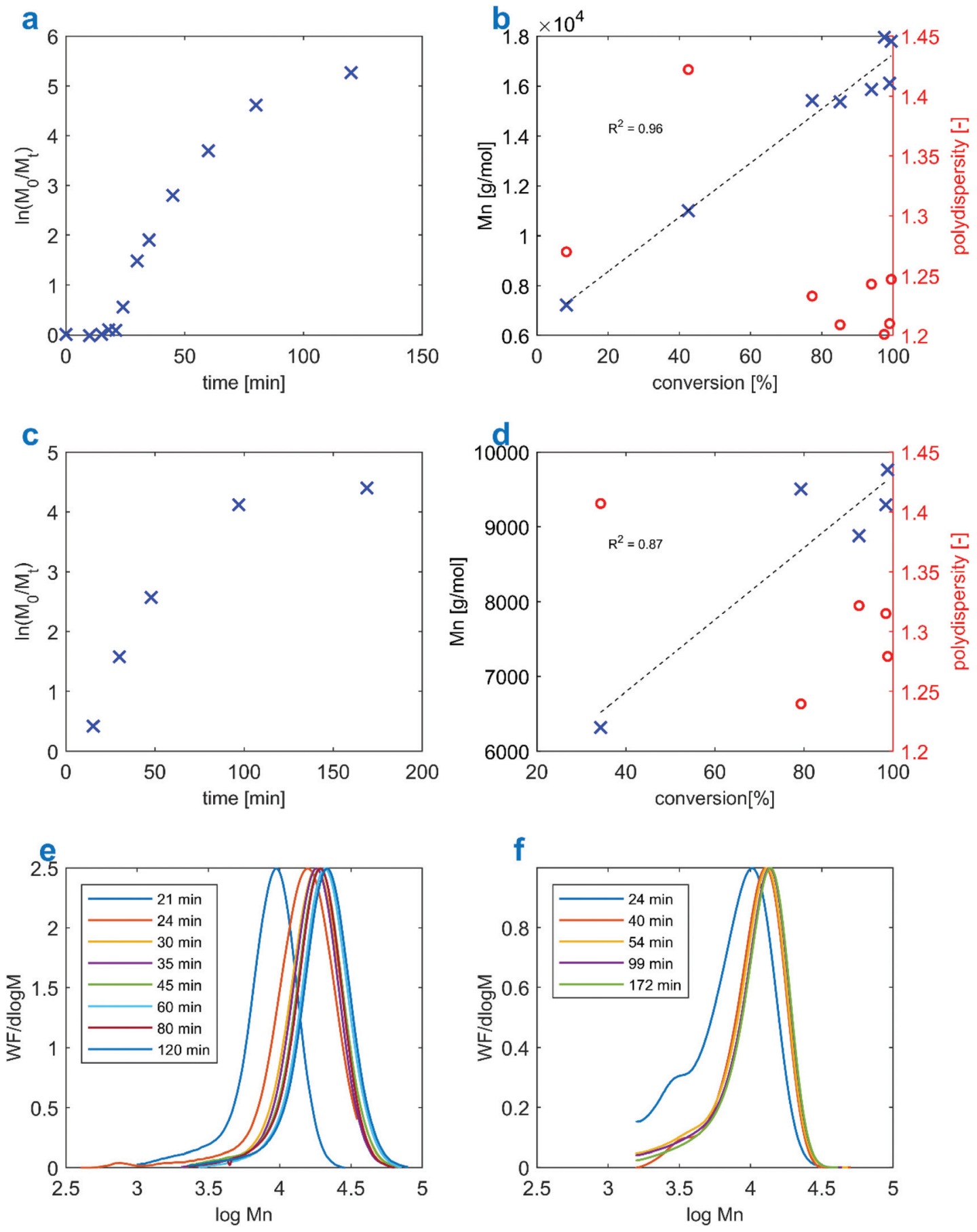

Fig. 1 Comparison between the polymerization kinetics of the Et ${ }_{3} \mathrm{~N}-\mathrm{AMPS}$ monomer involving two different RAFT agents: BDMAT and CVPTTC. Reactions correspond to Table 1 entries: 6 ( $a, b$, and e) and 12 (c, d, and f).

$300 \mathrm{~mm}$ ). The system used $10 \mathrm{mM}$ solution of LiBr in DMF at

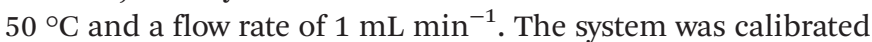
with polystyrene standards and used a toluene flow marker.

All aqueous solutions were recorded with the Agilent 1200 Series system using a PSS SUPREMA column and a PSS SECurity RI detector. The system was calibrated with polyacrylamide standards and an ethylene glycol flow marker. The eluent was $0.05 \mathrm{M} \mathrm{NaNO}_{3}$ with a $1.0 \mathrm{~mL} \mathrm{~min}^{-1}$ flow rate.

\section{Examples of PIL homopolymerization procedures}

Synthesis of $\left(\mathbf{E t}_{3} \mathbf{N} \text {-AMPS }\right)_{50}$-RAFT macroCTA. The RAFT polymerization of the $\mathrm{Et}_{3} \mathrm{~N}$-AMPS monomer targeting $\mathrm{DP}=50$ was carried out as follows: $10.1262 \mathrm{~g}$ (49.00 mmol) of AMPS was dissolved in $10 \mathrm{~mL}$ of water in a $100 \mathrm{~mL}$ round-bottom flask. While stirring, $6.82 \mathrm{~mL}(49.00 \mathrm{mmol})$ of triethylamine was added in small portions. Then, $27.6 \mathrm{mg}\left(9.8 \times 10^{-2} \mathrm{mmol}\right)$ 
of ACVA and $301.6 \mathrm{mg}\left(9.8 \times 10^{-1} \mathrm{mmol}\right)$ of CVPTTC were added into the flask, followed by $7.6 \mathrm{~mL}$ of water. After full dissolution, the flask was sealed with a rubber septum and purged with argon for 30 minutes, after which the flask was submerged in a $80{ }^{\circ} \mathrm{C}$ oil bath. The total reaction time was 120 minutes. Throughout the reaction, NMR and SEC samples were taken at predetermined time points. After the reaction, the mixture was precipitated in acetone, the produced solid was washed with acetone, and dried in an $80^{\circ} \mathrm{C}$ oven overnight, yielding a brittle, glassy yellow solid.

Free radical polymerization of $\mathbf{E t}_{3} \mathbf{N}$-AMPS. The conditions for this process were chosen to mimic the conditions for RAFT polymerization targeting DP $=200$ so that the influence of the RAFT agent could be assessed. $6.749 \mathrm{~g}$ (33.00 mmol) of AMPS was placed in a $100 \mathrm{~mL}$ round bottom flask. Then, a solution consisting of $4.5 \mathrm{mg}\left(1.6 \times 10^{-2} \mathrm{mmol}\right)$ of ACVA and $11.7 \mathrm{~mL}$ of DMSO was added into the flask, followed by portion-wise addition of $4.54 \mathrm{~mL}(33.00 \mathrm{mmol})$ of triethylamine. The mixture was stirred until full dissolution. The flask was sealed with a rubber septum and purged with argon for $30 \mathrm{~min}$, before submerging in the $80{ }^{\circ} \mathrm{C}$ oil bath. The total reaction time was 18 hours. The reaction mixture was precipitated in acetone, forming a white sticky solid. The solid was washed three times with acetone, dissolved in a minimal volume of water, washed three times with DCM to remove traces of DMSO, and precipitated again in acetone. The recovered solid was dried overnight at $80^{\circ} \mathrm{C}$.

\section{Examples of chain extension procedures}

Synthesis of $\left(\mathrm{Et}_{3} \mathbf{N} \text {-AMPS }\right)_{100}$-block-(S) $)_{15}$-RAFT diblock copolymer ("PAMPS-first"). $3.0463 \mathrm{~g}\left(9.78 \times 10^{-2} \mathrm{mmol}\right)$ of $\left(\mathrm{Et}_{3} \mathrm{~N} \text {-AMPS }\right)_{100}$-CVPTTC was placed in a $25 \mathrm{~mL}$ round bottom flask along with $3.7 \mathrm{~mL}$ of DMSO and stirred overnight at $50{ }^{\circ} \mathrm{C}$ until dissolution. Upon cooling down, $2.6 \mathrm{mg}(9.28 \times$ $10^{-3} \mathrm{mmol}$ ) of ACVA was added and the mixture was purged with argon for $30 \mathrm{~min}$. Then, $170 \mu \mathrm{L}$ of styrene $(1.48 \mathrm{mmol})$ was added into the main reaction flask with an argon-flushed syringe. The flask was sealed gastight with a rubber septum and the reaction was started by placing it in the $80^{\circ} \mathrm{C}$ oil bath. The total reaction time was 52 hours. Styrene conversion was tracked using ${ }^{1} \mathrm{H}$ NMR in $\mathrm{d}_{6}$-DMSO. The reaction mixture was precipitated in acetone. This yielded a sticky yellow solid, which was washed with acetone, dissolved in a minimal volume of water, and extracted three times with DCM to remove traces of DMSO. The polymer was recovered from the solution by precipitation in acetone, after which it was dried in the $80^{\circ} \mathrm{C}$ oven overnight, yielding a glassy yellow solid.

Synthesis of $\left(S_{11} \text {-block-( } \mathrm{Et}_{3} \mathrm{~N} \text {-AMPS }\right)_{50}$-RAFT diblock copolymer ("PS-first"). $174.8 \mathrm{mg}\left(1.25 \times 10^{-1} \mathrm{mmol}\right)$ of $\mathrm{S}_{11}$-MCEBTTC macroRAFT agent was dissolved in $2.25 \mathrm{~mL}$ of DMF in a $25 \mathrm{~mL}$ round bottom flask. To that, $1.9411 \mathrm{~g}(6.29 \mathrm{mmol})$ of the freshly prepared $\mathrm{Et}_{3} \mathrm{~N}$-AMPS monomer and $4.0 \mathrm{mg}\left(2.44 \times 10^{-2}\right.$ $\mathrm{mmol}$ ) of AIBN were added. The flask was sealed with a rubber septum and the contents were purged with argon for $30 \mathrm{~min}$. The reaction was started by placing the flask in the $80^{\circ} \mathrm{C}$ oil bath. The total reaction time was 43 hours. The reaction mixture was quenched by exposing it to air and precipitating in acetone. The obtained sticky solid was washed with acetone, dissolved in a minimal volume of water and washed three times with DCM. The product was precipitated in acetone and dried in the $80^{\circ} \mathrm{C}$ oven overnight, obtaining a glassy yellow solid.

\section{Results and discussion}

\section{$\mathrm{Et}_{3} \mathrm{~N}$-AMPS homopolymerization}

In order to estimate the reactivity and degree of control over the RAFT process, the $\mathrm{Et}_{3} \mathrm{~N}$-AMPS monomer has been compared with Na-AMPS with respect to its behavior in a polymerization reaction. Table 1 summarizes the homopolymerization reactions. Several observations can be made on the polydispersity of the $\mathrm{P}\left(\mathrm{Et}_{3} \mathrm{~N}\right.$-AMPS $)$ polymers as a function of the solvent and RAFT agent employed. When BDMAT is used with water as solvent, the PDI values are approximately in the range 1.3-1.4, which is significantly less than the value for a product of free radical polymerization, with $\mathrm{PDI}=3.16$; this confirms that the RAFT agent is effective. A clear trend of PDI increasing with the targeted degree of polymerization (DP) can be identified, with the maximal values of 1.6-1.7 occurring for a reaction involving CVPTTC and targeting DP $=200$. The discrepancy between the effects of BDMAT and CVPTTC on the final PDI value could be due to the BDMAT RAFT agent releasing a more reactive radical in the course of the RAFT mechanism, but it could also be explained by a known effect of improved control over acrylate polymerization in water over other solvents. ${ }^{48}$ The differences between both RAFT agents are discussed in the following section. Interestingly, the results when using CVPTTC seem to be nearly independent of the solvent, with water yielding only slightly lower PDIs than DMSO, at a given target DP. Conducting the aqueous process at a temperature of $50{ }^{\circ} \mathrm{C}$ instead of $80{ }^{\circ} \mathrm{C}$ is another way to reduce the PDI, albeit at a cost of a significantly slower rate of conversion. With the NaAMPS monomer, a similar PDI vs. DP trend is observed; however, the PDI values are clearly lower, even for DP $=200$. Unlike $\mathrm{Et}_{3} \mathrm{~N}$-AMPS, Na-AMPS seems to produce consistent PDI values irrespective of the choice of the RAFT agent. The conversion rates are similar in both monomers, and near-quantitative conversion is reached in 2-3 hours at $80^{\circ} \mathrm{C}$. The homopolymerization of $\mathrm{Et}_{3} \mathrm{~N}$-AMPS is also possible in ethanol (Table 1 entry 13), as both the monomer and the polymer are soluble in this solvent. This reaction has not been studied by us in detail, as its purpose is demonstration of the feasibility of using yet another solvent for the described process and chain extension with styrene could give solubility problems; however, a kinetics plot and a SEC trace of the product are available in the ESI (Fig. S5†). Similarly, Table 1 entry 14 refers to an attempt to polymerize the AMPS form in DMSO. We found that the product of this reaction is unstable, presumably owing to the presence of strongly acidic non-neutralized sulfonate moieties. See the ESI (Fig. S6†) for a photograph of the decomposed sample and an ${ }^{1} \mathrm{H}$ NMR spectrum. 
Table 1 A comparison between the outcomes of $\mathrm{Et}_{3} \mathrm{~N}$-AMPS homopolymerization and Na-AMPS homopolymerization, under various conditions

\begin{tabular}{|c|c|c|c|c|c|c|c|c|c|c|c|}
\hline Entry & Monomer & $\begin{array}{l}\text { Target } M_{\mathrm{n}} \\
{\left[\mathrm{kg} \mathrm{mol}{ }^{-1}\right](\mathrm{DP})}\end{array}$ & {$[\mathrm{CTA}]_{0} /[\mathrm{I}]_{0}$} & {$[\mathrm{M}]_{0}$} & $\begin{array}{l}\text { RAFT } \\
\text { agent }\end{array}$ & Solvent & $\begin{array}{l}\text { Temp. } \\
{\left[{ }^{\circ} \mathrm{C}\right]}\end{array}$ & 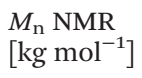 & 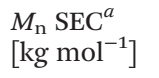 & PDI, SEC & $\begin{array}{l}\text { Conversion } \\
{[\%]}\end{array}$ \\
\hline 1 & $\mathrm{Et}_{3} \mathrm{~N}-\mathrm{AMPS}$ & $15.2(48)$ & 10.0 & 1.13 & CVPTTC & DMSO & 80 & 13.8 & 15.4 & 1.24 & 85 \\
\hline 2 & & $12.9(41)$ & 9.1 & 2.9 & CVPTTC & & 80 & 13.0 & 17.3 & 1.24 & 99 \\
\hline 3 & & $62.0(200)$ & 5.0 & 3.0 & CVPTTC & & 80 & 30.3 & 35.5 & 1.70 & 96 \\
\hline 4 & & $62.0(200)$ & 10.0 & 2.0 & CVPTTC & & 80 & 26.1 & 29.3 & 1.60 & 95 \\
\hline 5 & & FRP & FRP & 2.0 & CVPTTC & & 80 & - & 45.2 & 3.16 & 98 \\
\hline 6 & & $15.7(50)$ & 10.0 & 2.0 & CVPTTC & Water & 80 & - & See Fig. 1B & See Fig. 1B & See Fig. 1B \\
\hline 7 & & $31.2(100)$ & 10.0 & 2.0 & CVPTTC & & 70 & - & 30.7 & 1.31 & 100 \\
\hline 8 & & $62.0(200)$ & 10.0 & 2.0 & CVPTTC & & 80 & 27.8 & 59.1 & 1.64 & 99 \\
\hline 9 & & $62.0(200)$ & 10.0 & 2.0 & CVPTTC & & 50 & - & 46.2 & 1.55 & 98 \\
\hline 10 & & $62.0(200)$ & 10.0 & 2.0 & BDMAT & & 80 & - & 48.0 & 1.34 & 100 \\
\hline 11 & & $62.0(200)$ & 10.0 & 2.0 & BDMAT & & 60 & - & 61.7 & 1.39 & 100 \\
\hline 12 & & $15.7(50)$ & 10 & 2.0 & BDMAT & & 70 & - & See Fig. 1D & See Fig. 1D & See Fig. 1D \\
\hline 13 & & $6.4(20)$ & 10 & 1.5 & BDMAT & Ethanol & Reflux & - & 6.5 & 1.26 & 95 \\
\hline 14 & AMPS acid & 37.1 (178) & 9 & 2.2 & BDMAT & DMSO & 80 & - & - & - & 95 \\
\hline 15 & Na-AMPS & $1.1(5)$ & 9.12 & 1.73 & CVPTTC & Water & 70 & - & 4.0 & 1.25 & 100 \\
\hline 16 & & $4.6(20)$ & 5.09 & 2.0 & CVPTTC & & 70 & - & 8.4 & 1.17 & 100 \\
\hline 17 & & $11.5(50)$ & 12 & 2.0 & BDMAT & & 80 & - & 21.0 & 1.23 & 100 \\
\hline 18 & & $19.5(85)$ & 4.85 & 2.0 & CVPTTC & & 70 & - & 20.4 & 1.20 & 100 \\
\hline 19 & & $45.8(200)$ & 10 & 2.0 & CVPTTC & & 80 & - & 41.8 & 1.30 & 99 \\
\hline
\end{tabular}

${ }^{a}$ Measured in $0.05 \mathrm{M} \mathrm{NaNO}_{3}$ eluent. ${ }^{b}$ Measured by NMR; $100 \%$ means no integrable vinyl signals.

The kinetics of $\mathrm{Et}_{3} \mathrm{~N}$-AMPS homopolymerization was investigated in detail. To this end, two RAFT polymerization reactions targeting DP $=50$ were conducted in water, each using a different RAFT agent. Both processes were studied by tracking the conversion, $M_{\mathrm{n}}$ and PDI with time. Fig. $1 \mathrm{~B}$ and D show that the evolution of molecular weight with conversion is approximately linear for both reactions, as expected for a controlled process. The PDIs also decrease over time, which is typical of RAFT. $^{49}$ Comparing Fig. 1A with C, it can be seen that in both cases the kinetics conforms to the pseudo-first-order model; what stands out, however, is the presence of a significant induction period (taking up approximately 25\% of the total reaction time) for the reaction using the CVPTTC RAFT agent, which is virtually absent for the process using BDMAT. In general, such an induction period indicates either a slow propagation constant of the monomer or insufficient re-initiating capability of the $\mathrm{R}^{\cdot}$ radical. ${ }^{50}$ In this case, the latter is speculated to be more probable, as the cyano-stabilized tertiary radical from CVPTTC is far more stable than a radical formed from BDMAT.

\section{Chain extension experiments}

Before proceeding to the synthesis of amphiphilic block copolymers, to investigate chain end retention, we conducted chain extension experiments with $\mathrm{Et}_{3} \mathrm{~N}$-AMPS on a $\mathrm{P}\left(\mathrm{Et}_{3} \mathrm{~N}-\mathrm{AMPS}\right)_{20}$ macroRAFT agent. In this way, the polymer could be characterized by aqueous SEC without the need to switch to a different solvent and column. Fig. 2 shows the pseudo- $1^{\text {st }}$ order kinetics and the evolution of the molecular weight and PDI. The SEC traces were monomodal and shifted to higher molecular weights as the reaction progressed, which indicates that the process was controlled and that the macroCTA had a high proportion of living chains.
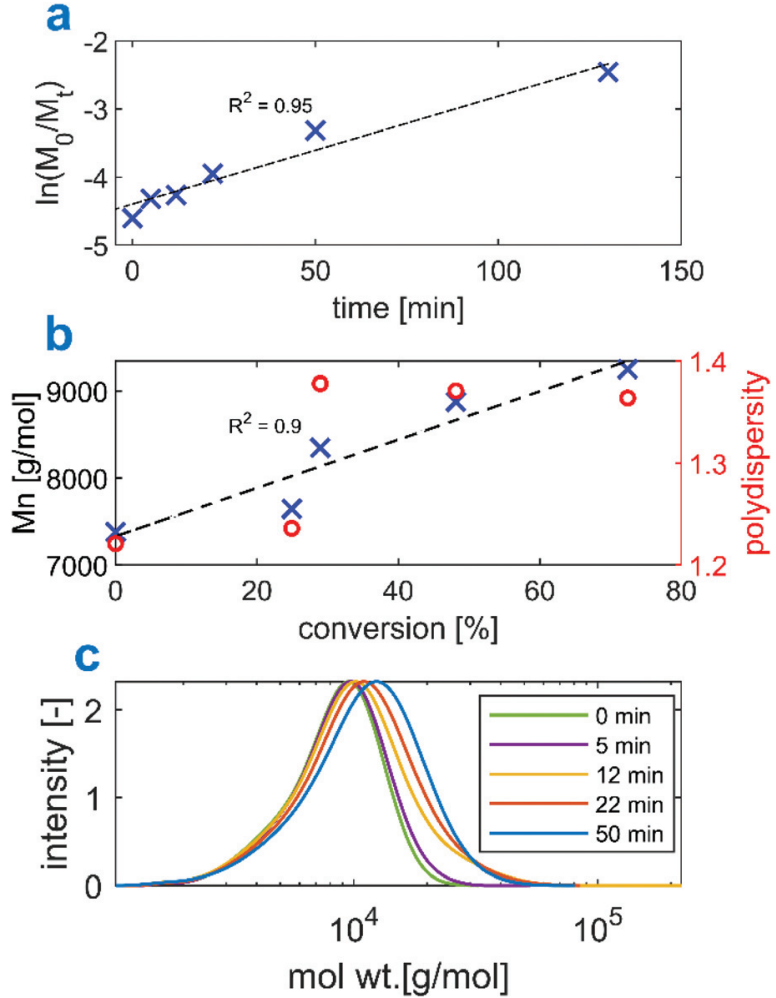

Fig. 2 Kinetic study of a polymerization of $\mathrm{Et}_{3} \mathrm{~N}-\mathrm{AMPS}$ using a $\mathrm{P}\left(\mathrm{Et}_{3} \mathrm{~N}-\mathrm{AMPS}\right)-\mathrm{BDMAT} \mathrm{RAFT}$ agent.

\section{Synthesis of amphiphilic diblocks}

Amphiphilic diblock copolymers were synthesized by following either the "PAMPS-first" or "PS-first" approach. In the first type of reaction, the hydrophobic monomer styrene is polymer- 
ized in the presence of $\mathrm{P}\left(\mathrm{Et}_{3} \mathrm{~N}-\mathrm{AMPS}\right)-\mathrm{RAFT}$ macroCTA, while in the other case the $\mathrm{Et}_{3} \mathrm{~N}$-AMPS monomer is polymerized in the presence of PS-RAFT macroCTA. All the reaction conditions, along with the attained conversions, SEC results and DOSY diffusion coefficients are summarized in Table 2. Even though the homopolymerization of $\mathrm{Et}_{3} \mathrm{~N}$-AMPS using CVPTTC or BDMAT RAFT agents is rapid (approx. 2 hours of reaction time) and results in near-quantitative conversion, it is not the case for polymerization using polystyrene macroCTA. The attained conversions for all "PS-first" chain extensions (entries 1-4 in Table 2) were never full, despite over 20 hours of polymerization time (also see Fig. S7 $\dagger$ ). This can be attributed to the fact that in the "PS-first" scheme, the less-activated monomer (styrene) is polymerized first, while from the point of view of the RAFT mechanism it is advantageous to first polymerize the more-activated monomer. The dispersity values reported for all "PS-first" reactions (entries 1-4 in Table 2) are between 1.08 and 1.21. While these values are low and therefore suggest very good control over the polymerization, they may have been affected by the purification by acetone reprecipitation, which can selectively separate dead PS chains and shorter diblocks. This may also explain the overshot PAMPS/PS ratios and $M_{\mathrm{n}}$ values, measured by NMR and SEC, respectively.

After purification by precipitation in acetone, the polymers were characterized by ${ }^{1} \mathrm{H}-\mathrm{NMR}$, UV-VIS, elemental analysis, ${ }^{1} \mathrm{H}$ DOSY, and DLS. Results for the sample from entry 9 can be seen in Fig. 3. The UV-VIS spectrum of the $10 \mathrm{mg} \mathrm{mL}^{-1}$ aqueous solution of the diblock product features several weak bands in the range $250-280 \mathrm{~nm}$, which confirm the presence of aromatic compounds in the product. The spectra were recorded in aqueous solutions, as both DMSO and DMF absorb UV light in the region of interest. Therefore, the signals may have been attenuated by the formation of PS-core self-assembled structures in the solution. A qualitative presence, however, is clearly visible when compared with a homopolymer macroCTA's spectrum (Fig. 3A). Similar observation can be made for the remaining samples in Table 2 (see Fig. S9†).

The presence of styrene units in the copolymer is also evident from the NMR spectra in Fig. 3C, showing two broad peaks around $6.5 \mathrm{ppm}$ and $7.1 \mathrm{ppm}$ coming from the polystyrene block, which are not present in the spectrum of the homopolymer (for more ${ }^{1} \mathrm{H}-\mathrm{NMR}$ spectra see Fig. S3 ${ }^{\dagger}$ ). As the aromatic signals might be subject to significant intensity changes following chain self-assembly, ${ }^{20,51}$ we calculated the diblocks' compositions only based on NMR spectra recorded with a high recycle delay of $d 1=30 \mathrm{~s}$. The aromatic peaks are overlapped with the amide proton peak from AMPS, which can be deconvoluted in the software before integration. Finally, to further demonstrate that the polystyrene blocks are covalently joined with the $\mathrm{P}\left(\mathrm{Et}_{3} \mathrm{~N}\right.$-AMPS) blocks, ${ }^{1} \mathrm{H}$-DOSY experiments were performed. Briefly, this method allows us to assign a diffusion coefficient to every peak in an ${ }^{1} \mathrm{H}-\mathrm{NMR}$ spectrum. If two peaks are assigned similar diffusion coefficients, it can be inferred they come from the same molecule. In the ${ }^{1} \mathrm{H}$-DOSY plot in Fig. 3D, both the polystyrene signal at around $6.5 \mathrm{ppm}$

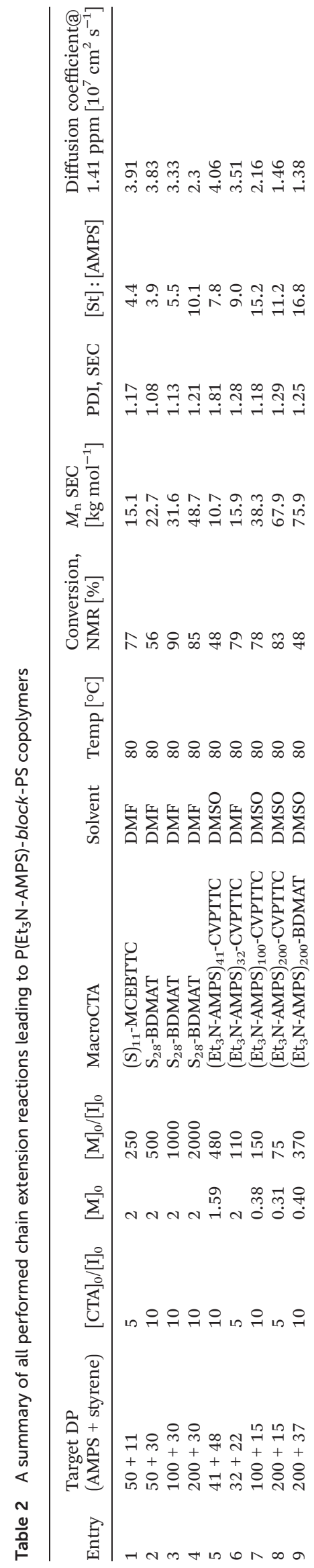

Polym. Chem., 2021, 12, 5505-5517 | 5511 
a

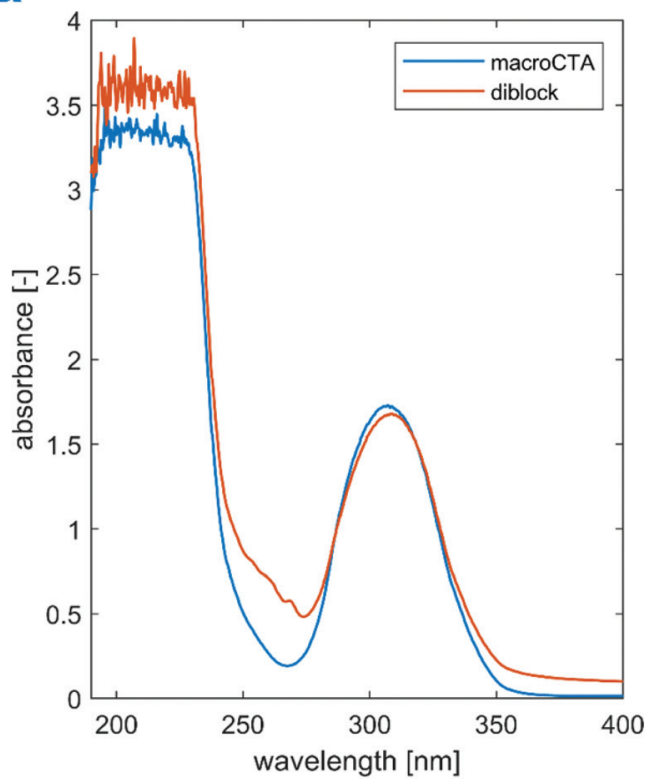

C
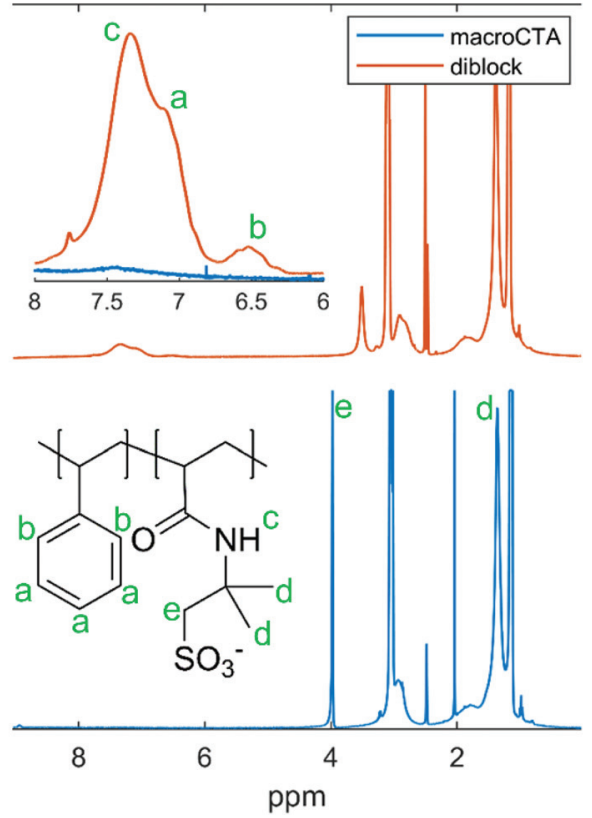
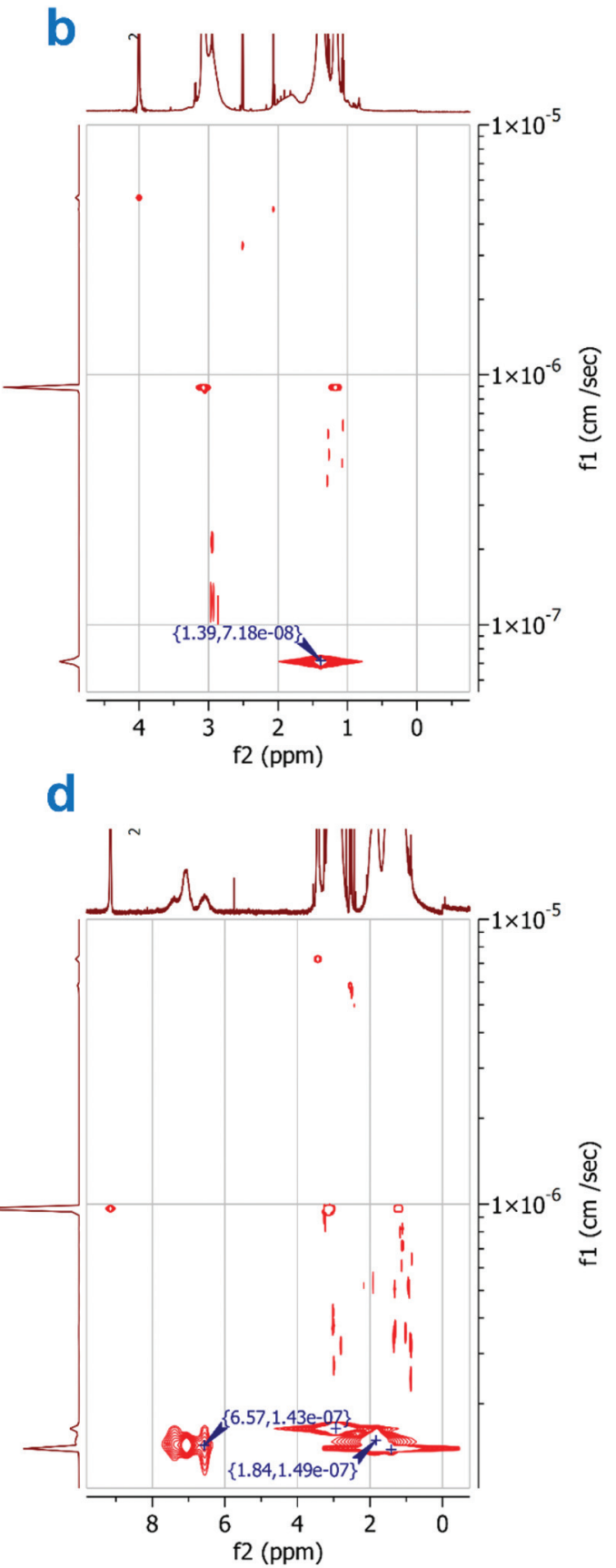

Fig. 3 Comparison between a (Et $\left.{ }_{3} \mathrm{~N}-\mathrm{AMPS}\right)_{200}$ macroCTA and an amphiphilic diblock produced from it (Table 2 entry 9): A - UV-VIS spectra of a $10 \mathrm{mg} \mathrm{mL}^{-1}$ aqueous solutions, $\mathrm{B}-{ }^{1} \mathrm{H}$ DOSY projection of the macroCTA, C $-{ }^{1} \mathrm{H}$ NMR in $\mathrm{d}_{6}$-DMSO (amide proton signal in the macroCTA's spectrum has been cleared by the addition of $\mathrm{D}_{2} \mathrm{O}$ ), and $\mathrm{D}-{ }^{1} \mathrm{H}$ DOSY projection of the diblock.

and the $-\mathrm{CH}_{3}$ AMPS signal at 1.39 ppm have a diffusion coefficient close to $10^{-7} \mathrm{~cm}^{2} \mathrm{~s}^{-1}$, characteristic of a very large molecule. Thus, we conclude that the architecture of the products is indeed that of a diblock copolymer. A similar conclusion can be drawn for all the samples listed in Table 2 (see Fig. S10 $\dagger$ ). The small variations in the measured diffusion coefficients for AMPS and aromatic peaks are a result of a single-exponential fitting and are expected. Elemental analysis results for entry 9, which confirm a smaller proportion of nitrogen in the diblock product, compared with the macroCTA, are available in Table S1 (ESI $\dagger$ ).

\section{SEC analysis of the amphiphilic diblock copolymers}

All the diblock samples outlined in Table 2 along with their corresponding macroCTAs have been analysed using a an SEC system using DMF (Fig. 4). The diblocks' peaks are monomodal, indicating a high end-group retention in the macroCTAs. The shifting of the SEC traces towards lower elution volumes 

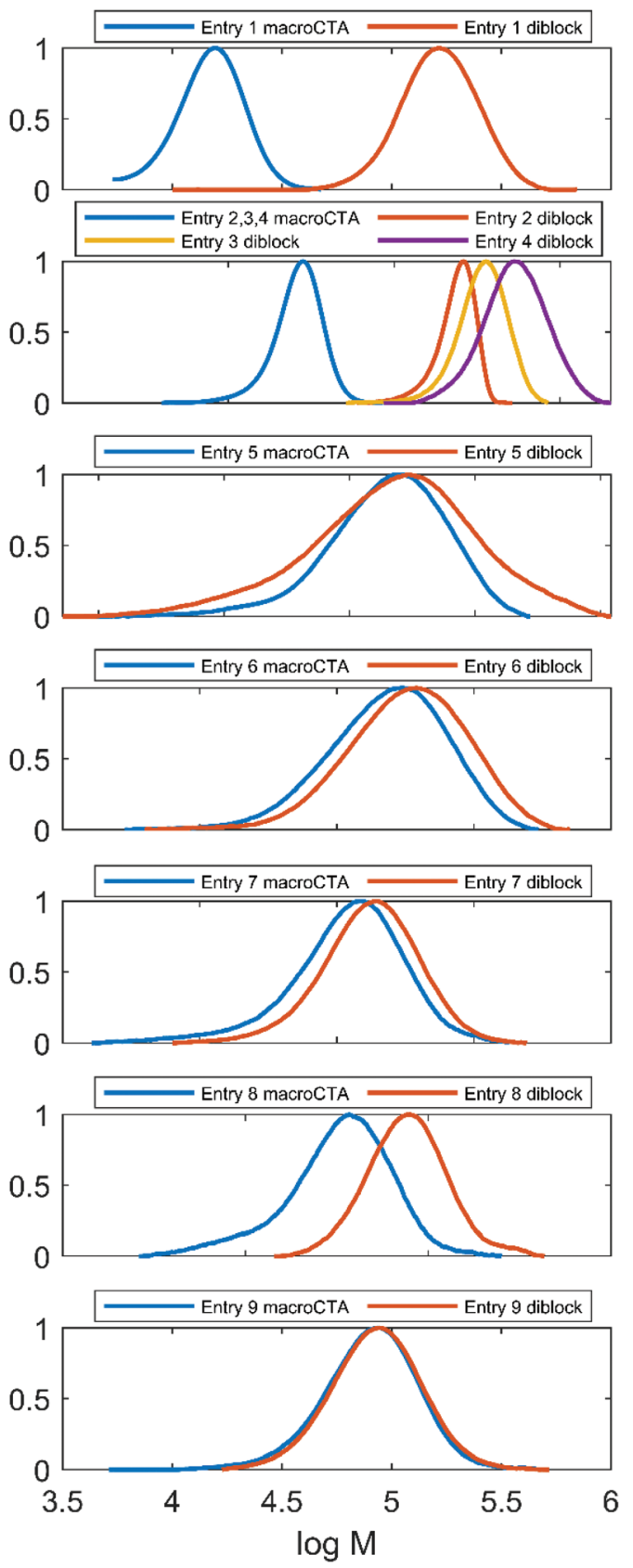

Fig. 4 SEC traces in DMF/LiBr of all amphiphilic diblock copolymers enumerated in Table 2, together with the corresponding macroCTAs. The anomalous peak "shuffling" is discussed in text.

in the course of the chain extension process was not reliable. This unusual behavior is likely a consequence of the diblock structure. Problematic SEC characterization of block copolymers has been recently outlined, ${ }^{52}$ stressing that aspects such as a rod-coil architecture and strong block-block and blockcolumn interactions exacerbate this issue. In the case of $\mathrm{Et}_{3} \mathrm{~N}$-AMPS-block-St copolymers, the extreme difference in polarities of the blocks and the difference in block rigidities are factors that could cause such behavior. Further evidence that this effect is related to non-ideal chain behavior comes from the fact that it seems to depend on the type of column used (compare Fig. 4 to Fig. S11, $\uparrow$ which contains SEC traces for the same samples, measured using a different SEC apparatus with the DMF eluent).

This phenomenon is observed only for some of the "PAMPS-first" samples (entries 5-9, Fig. 4), while the "PS-first" SEC traces behave as expected (entries 1-4, Fig. 4). In order to establish whether the "PAMPS-first" is a valid method of producing the amphiphilic diblock copolymers, we examined this effect in more detail, as follows. A "PAMPS-first" reaction has been performed, targeting a large $(\mathrm{DP}=200)$ molecular weight of the polystyrene block, in order to maximize the chances that the SEC peak shifting would be visible. DMF SEC samples were drawn periodically from the reaction (Fig. S12 $\dagger$ ). The trace at $t=0$ min corresponds to the $\mathrm{P}\left(\mathrm{Et}_{3} \mathrm{~N}\right.$-AMPS $)$ homopolymer macroCTA. Interestingly, the samples taken at short times (low styrene conversion) produced SEC traces that were shifted to lower apparent molecular weights than that of the macroCTA. However, within the series of traces corresponding to the growing diblock, the shifting is monotonic towards higher molecular weights, as expected. Therefore, there seems to be a discontinuity in the behavior of the polymer chains in the SEC system as the type of polymer changes from a homopolymer to an amphiphilic diblock. This initial shift towards lower apparent molecular weights has to be overcome by growing the polystyrene chain by a given amount of units before the measured "net" trace is shifted in the expected direction with respect to the original macroCTA. Indeed, an analogous situation is described for highly incompatible block copolymer systems in the previously cited work, ${ }^{52}$ where the elution time initially increases as the block copolymer is formed.

The discussed effect could be sufficient to explain the unreliable SEC trace shifting of some entries in Table 2. In "PAMPS-first" reactions, the targeted low DP of the polystyrene block along with non-quantitative conversions of the styrene monomer means that the expected increment in molecular weight is always low (ranging from approximately $2 \%$ for the sample in entry 8 to $19 \%$ for entry 5 ). As discussed above, this increment might not have always been enough to compensate for the initial lowering of the apparent molecular weight. On the other hand, for "PS-first" reactions, the expected molecular weight increment was always large, ranging from $300 \%$ for entry 2 to $1800 \%$ for entry 4 . Given this explanation and the fact that other presented results do not differentiate between the "PS-first" and "PAMPS-first" methods, we conclude that both are valid approaches towards the synthesis of PS-blockPAMPS amphiphilic block polyelectrolytes.

Formation of an amphiphilic product was further confirmed by studying the properties of its aqueous solution. Fig. 5A shows the comparison between hydrodynamic diameters, measured by DLS, of $0.5 \%$ solutions of $\mathrm{P}\left(\mathrm{Et}_{3} \mathrm{~N}-\mathrm{AMPS}\right)$ macroCTAs and $0.5 \%$ solutions of the corresponding diblock products. In every case, the diameters measured in the solutions of the copolymers were close to or above $100 \mathrm{~nm}$, while the macroCTAs were close to $1 \mathrm{~nm}$. This indicates that, in fact, 

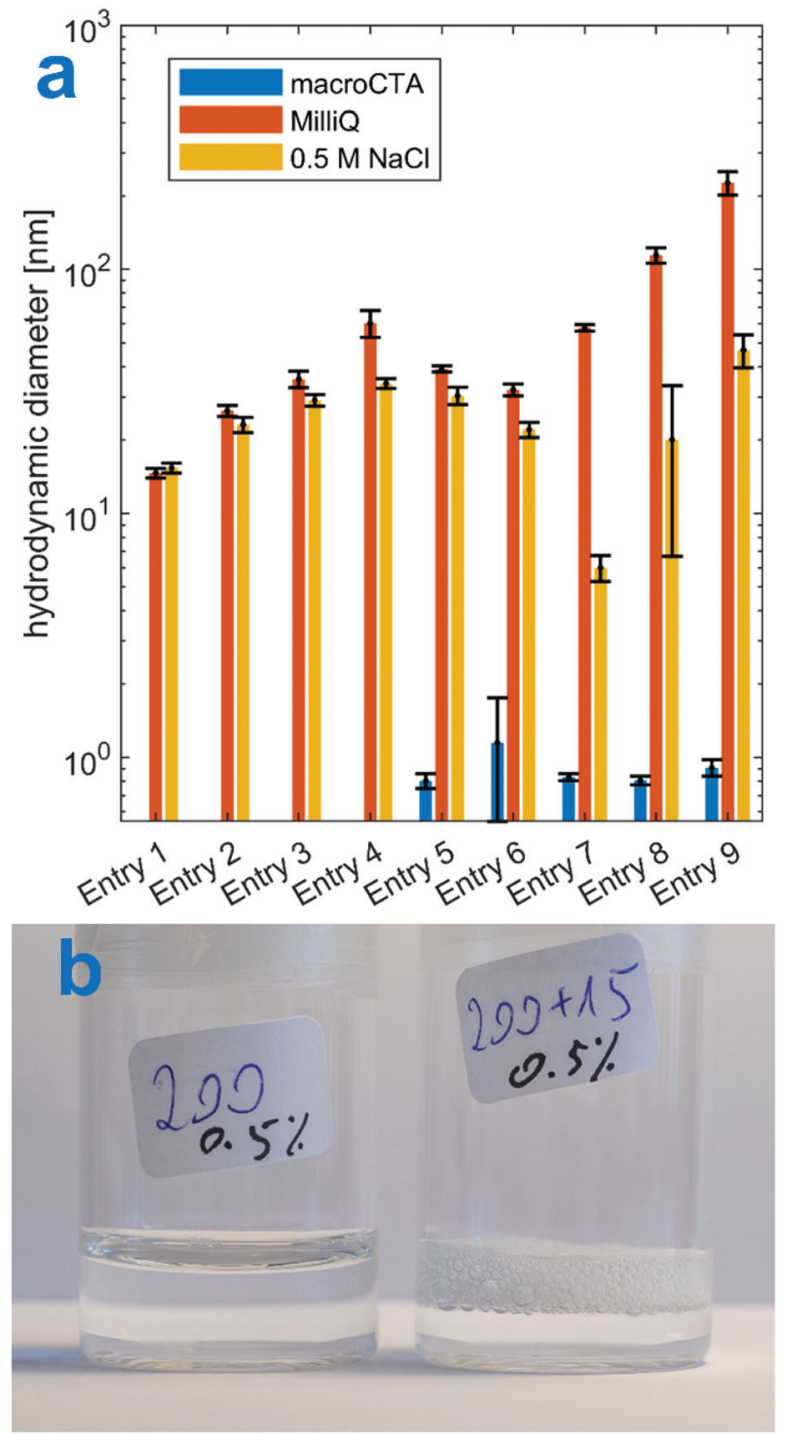

Fig. 5 Solution properties of the amphiphilic diblocks. A: DLS comparison between hydrophilic macroCTAs and amphiphilic diblock copolymers. Entries correspond to those in Table $2 \mathrm{~B}$ : appearance of $0.5 \mathrm{wt} \%$ aqueous solutions of Table 2 entry 8 macroCTA (left) and diblock (right), after being shaken by hand for $30 \mathrm{~s}$ and left steady for $15 \mathrm{~min}$.

the copolymers form self-assembled structures in solution, while the macroCTAs (being fully hydrophilic) do not. Furthermore, upon addition of salt solution to the diblock DLS samples, their hydrodynamic diameters decreased in allbut-one case. This could be attributed to the collapse of the negatively charged coronas as a result of increased ionic strength, although this cannot be stated conclusively as the effects related to the thickness of the electrical double layer could also play a role. Note that the DLS results shown here have not been corrected for viscosity, which is bound to introduce a small positive error in the absolute values of the hydrodynamic diameters, but it is unlikely to affect the overall discussed trend. DLS number-average diameter distributions and the values of number-average mean diameters, $Z$-average mean diameters and polydispersity indices are shown in Fig. S8 and Table S2. $\dagger$ As a final piece of evidence towards the amphiphilic nature of the copolymers, the photograph in Fig. 5B shows the formation of persistent foam after agitation of a $0.5 \%$ diblock solution, while the foam does not persist in the macroCTA solution. Observation of foaming has been used before as a qualitative test of interfacial adsorption of amphiphilic species. $^{53-56}$

\section{Conclusions}

There are several approaches available to synthesize strongly ionic amphiphilic block copolymers. The main practical difficulty with many of these systems is the high incompatibility of a polyelectrolytic block and a strongly hydrophobic one. Heterogeneous methods, such as PISA, ${ }^{29}$ can be applied, as well as methods based on protection-deprotection chemistry. ${ }^{26,28}$ Some anionic monomers, when in acid form, may also be polymerizable in universal solvents such as $\mathrm{DMSO}^{21}$ or NMP. ${ }^{20}$ In this work, we have shown that it might be advantageous to proceed via RAFT polymerization of a poly (ionic liquid), obtained by neutralizing the monomer (here AMPS) with an organic amine such as triethylamine, in order to ensure the solubility of the resulting polymer macroCTA in organic solvents. In particular, we showed that AMPS-blockstyrene copolymers can be prepared by homogeneous RAFT using either a "PAMPS-first" or a "PS-first" approach, with the latter being slower, but providing lower dispersities, in various organic solvents, such as DMF or DMSO. The polymerization kinetics has been followed, and the formation of block copolymers with good control and high end-group fidelity has been demonstrated with the support of chain extension experiments and several characterization methods such as ${ }^{1} \mathrm{H}-\mathrm{NMR}$, UV-vis, SEC, ${ }^{1} \mathrm{H}$-NMR-DOSY, and DLS.

The design of the homogeneous RAFT process is easier than that for emulsion polymerization, and additionally the acidic monomer is neutralized, which prevents polymer degradation and allows for facile SEC characterization, both in organic and aqueous eluents. The improvement over protection-deprotection methods is the reduced number of steps and the lack of chemical alterations to the monomer, which tend to reduce the overall yield. The last step of cation exchange leads to the final sodium-salt product (see Fig. S4 in the ESI $\dagger$ ), suitable for areas of application where the presence of common inorganic ions is more desirable, such as industrial water viscosifiers and polymeric surfactants.

Since the process is homogeneous, we have demonstrated here that it is possible to arrive at the block copolymer either by hydrophilic-first or hydrophobic-first sequences, which would not work with PISA without changing the emulsion type. Even though there might be other requirements of the order of monomer addition stemming from the RAFT mechanism, this is still an advantage given the difficulties in studying the diblock product with SEC: as the macroCTA homopolymer can usually be fully characterized, it is possible to design 
the synthetic procedure according to research requirements, for instance for structure-property relationship studies, when the characterization of one of the blocks could be more important or difficult than the other.

We believe that this work provides an interesting alternative to existing methods of synthesis of amphiphilic block polyelectrolytes characterized by a strongly hydrophobic block. This approach could be expanded to other anionic monomers. Further studies in this matter could also involve a thorough comparison of all available approaches, with respect to the reactivities of the monomer, attainable PDIs, stability of the products and reaction flexibility. Such a database would enable an informed choice for researchers wishing to access strongly anionic block copolymers. Finally, the characterization of solution behavior and aggregation of the obtained block copolymers is certainly within the scope of possible future research.

\section{Conflicts of interest}

There are no conflicts to declare.

\section{Acknowledgements}

This work is part of the research programme of DPI, project \#821, which is kindly acknowledged for funding.

\section{References}

1 A. K. Saikia, S. Aggarwal and U. K. Mandal, Preparation and Controlled Drug Release Characteristics of Thermoresponsive PEG/Poly (NIPAM-Co-AMPS) Hydrogels, Int. J. Polym. Mater., 2013, 62(1), 39-44, DOI: 10.1080/00914037.2012.664208.

2 S. Durmaz and O. Okay, Acrylamide/2-Acrylamido-2Methylpropane Sulfonic Acid Sodium Salt-Based Hydrogels: Synthesis and Characterization, Polymer, 2000, 41(10), 3693-3704, DOI: 10.1016/S0032-3861(99)00558-3.

3 H. Bouhamed, S. Boufi and A. Magnin, Dispersion of Alumina Suspension Using Comb-like and Diblock Copolymers Produced by RAFT Polymerization of AMPS and MPEG, J. Colloid Interface Sci., 2007, 312(2), 279-291, DOI: 10.1016/j.jcis.2007.03.060.

4 H. Müller, W. Leube, K. Tauer, S. Förster and M. Antonietti, Polyelectrolyte Block Copolymers as Effective Stabilizers in Emulsion Polymerization, Macromolecules, 1997, 30(8), 2288-2293, DOI: 10.1021/ma9615516.

5 S. Zhong, X. Cui, H. Cai, T. Fu, K. Shao and H. Na, Crosslinked SPEEK/AMPS Blend Membranes with High Proton Conductivity and Low Methanol Diffusion Coefficient for DMFC Applications, J. Power Sources, 2007, 168(1), 154-161, DOI: 10.1016/j.jpowsour.2007.03.028.

6 A. Scott, M. Riahinezhad and A. Penlidis, Optimal Design for Reactivity Ratio Estimation: A Comparison of Techniques for AMPS/Acrylamide and AMPS/Acrylic Acid
Copolymerizations, Processes, 2015, 3(4), 749-768, DOI: 10.3390/pr3040749.

7 F. Li, W. Zhu, D. Yu, H. Song and K. Wang, Rheological Properties and Enhanced Oil Recovery Performance of a Novel Sulfonate Polyacrylamide, J. Macromol. Sci., Part A: Pure Appl.Chem., 2018, 55(6), 449-454, DOI: 10.1080/ 10601325.2018.1470462.

8 X. Yu, W. Pu, D. Chen, J. Zhang, F. Zhou, R. Zhang and S. Gu, Degradable Cross-Linked Polymeric Microsphere for Enhanced Oil Recovery Applications, RSC Adv., 2015, 5(77), 62752-62762, DOI: 10.1039/C5RA05366H.

9 K. Parkatzidis, H. S. Wang, N. P. Truong and A. Anastasaki, Recent Developments and Future Challenges in Controlled Radical Polymerization: A 2020 Update, Chem, 2020, 6(7), 1575-1588, DOI: 10.1016/j.chempr.2020.06.014.

10 S. Perrier, 50th Anniversary Perspective: RAFT Polymerization-A User Guide, Macromolecules, 2017, 50(19), 7433-7447, DOI: 10.1021/acs.macromol.7b00767.

11 R. Whitfield, K. Parkatzidis, N. P. Truong, T. Junkers and A. Anastasaki, Tailoring Polymer Dispersity by RAFT Polymerization: A Versatile Approach, Chem, 2020, 6(6), 1340-1352, DOI: 10.1016/j.chempr.2020.04.020.

12 B. S. Sumerlin, M. S. Donovan, Y. Mitsukami, A. B. Lowe and C. L. McCormick, Water-Soluble Polymers. 84. Controlled Polymerization in Aqueous Media of Anionic Acrylamido Monomers via RAFT, Macromolecules, 2001, 34(19), 6561-6564, DOI: 10.1021/ma011288v.

13 E. Read, A. Guinaudeau, D. James Wilson, A. Cadix, F. Violleau and M. Destarac, Low Temperature RAFT/ MADIX Gel Polymerisation: Access to Controlled Ultra-High Molar Mass Polyacrylamides, Polym. Chem., 2014, 5(7), 2202-2207, DOI: 10.1039/c3py01750h.

14 M. Semsarilar, V. Ladmiral, A. Blanazs and S. P. Armes, Anionic Polyelectrolyte-Stabilized Nanoparticles via RAFT Aqueous Dispersion Polymerization, Langmuir, 2012, 28(1), 914-922, DOI: 10.1021/la203991y.

15 C. Bray, R. Peltier, H. Kim, A. Mastrangelo and S. Perrier, Anionic Multiblock Core Cross-Linked Star Copolymers via RAFT Polymerization, Polym. Chem., 2017, 8(36), 55135524, DOI: 10.1039/C7PY01062A.

16 S. Bekhradnia, J. S. Diget, T. Zinn, K. Zhu, S. A. Sande, B. Nyström and R. Lund, Charged Star Diblock Copolymers in Dilute Solutions: Synthesis, Structure, and Chain Conformations, Macromolecules, 2015, 48(8), 2637-2646, DOI: $10.1021 / \mathrm{ma} 502488 \mathrm{u}$.

17 S. Yusa, Y. Shimada, Y. Mitsukami, T. Yamamoto and Y. Morishima, Heat-Induced Association and Dissociation Behavior of Amphiphilic Diblock Copolymers Synthesized via Reversible Addition-Fragmentation Chain Transfer Radical Polymerization, Macromolecules, 2004, 37(20), 7507-7513, DOI: 10.1021/ma0492519.

18 Y. Kotsuchibashi, M. Ebara, K. Yamamoto and T. Aoyagi, Tunable Stimuli-Responsive Self-Assembly System That Forms and Stabilizes Nanoparticles by Simple Mixing and Heating/Cooling of Selected Block Copolymers, Polym. Chem., 2011, 2(6), 1362-1367, DOI: 10.1039/c1py00004g. 
19 G. Masci, D. Bontempo, N. Tiso, M. Diociaiuti, L. Mannina, D. Capitani and V. Crescenzi, Atom Transfer Radical Polymerization of Potassium 3-Sulfopropyl Methacrylate: Direct Synthesis of Amphiphilic Block Copolymers with Methyl Methacrylate, Macromolecules, 2004, 37(12), 44644473, DOI: $10.1021 / \mathrm{ma} 0497254$.

20 S. Garnier and A. Laschewsky, Synthesis of New Amphiphilic Diblock Copolymers and Their Self-Assembly in Aqueous Solution, Macromolecules, 2005, 38(18), 75807592, DOI: 10.1021/ma0506785.

21 J. Garnier, J. Warnant, P. Lacroix-Desmazes, P.-E. Dufils, J. Vinas and A. van Herk, Sulfonated Macro-RAFT Agents for the Surfactant-Free Synthesis of Cerium Oxide-Based Hybrid Latexes, J. Colloid Interface Sci., 2013, 407, 273-281, DOI: $10.1016 /$ j.jcis.2013.06.037.

22 M. H. Allen, S. T. Hemp, A. E. Smith and T. E. Long, Controlled Radical Polymerization of 4-Vinylimidazole, Macromolecules, 2012, 45(9), 3669-3676, DOI: 10.1021/ ma300543h.

23 E. A. Hoff, B. A. Abel, C. A. Tretbar, C. L. McCormick and D. L. Patton, Aqueous RAFT at PH Zero: Enabling Controlled Polymerization of Unprotected Acyl Hydrazide Methacrylamides, Polym. Chem., 2017, 8(34), 4978-4982, DOI: $10.1039 / \mathrm{C} 6 \mathrm{PY} 01563 \mathrm{H}$.

24 C. Charbonneau, C. Chassenieux, O. Colombani and T. Nicolai, Controlling the Dynamics of SelfAssembled Triblock Copolymer Networks via the $\mathrm{PH}$, Macromolecules, 2011, 44(11), 4487-4495, DOI: 10.1021/ ma2002382.

25 E. Lejeune, M. Drechsler, J. Jestin, A. H. E. Müller, C. Chassenieux and O. Colombani, Amphiphilic Diblock Copolymers with a Moderately Hydrophobic Block: Toward Dynamic Micelles, Macromolecules, 2010, 43(6), 2667-2671, DOI: $10.1021 / \mathrm{ma9} 2822 \mathrm{~g}$.

26 P. Raffa, P. Brandenburg, D. A. Z. Wever, A. A. Broekhuis and F. Picchioni, Polystyrene-Poly(Sodium Methacrylate) Amphiphilic Block Copolymers by ATRP: Effect of Structure, PH, and Ionic Strength on Rheology of Aqueous Solutions, Macromolecules, 2013, 46(17), 7106-7111, DOI: 10.1021/ma401453j.

27 H. Mori, E. Kudo, Y. Saito, A. Onuma and M. Morishima, RAFT Polymerization of Vinyl Sulfonate Esters for the Controlled Synthesis of Poly(Lithium Vinyl Sulfonate) and Sulfonated Block Copolymers, Macromolecules, 2010, 43(17), 7021-7032, DOI: 10.1021/ma100905w.

28 A. H. Hofman, R. Fokkink and M. Kamperman, A Mild and Quantitative Route towards Well-Defined Strong Anionic/ Hydrophobic Diblock Copolymers: Synthesis and Aqueous Self-Assembly, Polym. Chem., 2019, 10(45), 6109-6115, DOI: 10.1039/C9PY01227C.

29 P. Gurnani, C. P. Bray, R. A. E. Richardson, R. Peltier and S. Perrier, Heparin-Mimicking Sulfonated Polymer Nanoparticles via RAFT Polymerization-Induced SelfAssembly, Macromol. Rapid Commun., 2019, 19.

30 S. L. Canning, G. N. Smith and S. P. Armes, A Critical Appraisal of RAFT-Mediated Polymerization-Induced Self-
Assembly, Macromolecules, 2016, 49(6), 1985-2001, DOI: 10.1021/acs.macromol.5b02602.

31 X. Wang and Z. An, New Insights into RAFT Dispersion Polymerization-Induced Self-Assembly: From Monomer Library, Morphological Control, and Stability to Driving Forces, Macromol. Rapid Commun., 2019, 40(2), 1800325, DOI: 10.1002/marc.201800325.

32 C. J. Ferguson, R. J. Hughes, D. Nguyen, B. T. T. Pham, R. G. Gilbert, A. K. Serelis, C. H. Such and B. S. Hawkett, $\mathrm{Ab}$ Initio Emulsion Polymerization by RAFT-Controlled Self-Assembly, Macromolecules, 2005, 38(6), 2191-2204, DOI: $10.1021 / \mathrm{ma} 048787 \mathrm{r}$.

33 J. Yuan and M. Antonietti, Poly(Ionic Liquid)s: Polymers Expanding Classical Property Profiles, Polymer, 2011, 52(7), 1469-1482, DOI: 10.1016/j.polymer.2011. 01.043.

34 J. C. Salamone, C. C. Tsai, A. P. Olson and A. C. Watterson, Ampholytic Polystyrene Ionomers from Cationic-Anionic Monomer Pairs, J. Polym. Sci., Polym. Chem. Ed., 1980, 18(10), 2983-2992, DOI: 10.1002/pol.1980.170181008.

35 T. Weng, J. Guo, X. Li, Y. Cui, X. Yang, K. Zhang, B. Zhang, G. Yin, S. V. Mikhalovsky, L. I. Mikhalovska, I. N. Savina, C. A. Howel and S. R. Sandeman, Synthesis of the Polymerizable Room Temperature Ionic Liquid AMPS TEA and Superabsorbency for Organic Liquids of Its Copolymeric Gels with Acrylamide, Des. Monomers Polym., 2014, 17(2), 140-146, DOI: 10.1080/15685551.2013.840480.

36 X. Yang, Y. Fang, X. Li, K. Zhang, Y. Cui, B. Zhang and G. Yin, Synthesis of Two AMPS-Based Polymerizable Room Temperature Ionic Liquids and Swelling Difference between Their Co-Polymeric Gels with HEMA, e-Polym., 2014, 14(5), 335-343, DOI: 10.1515/epoly-2014-0070.

37 H. Diao, F. Yan, L. Qiu, J. Lu, X. Lu, B. Lin, Q. Li, S. Shang, W. Liu and J. Liu, High Performance Cross-Linked Poly(2Acrylamido-2-Methylpropanesulfonic Acid)-Based Proton Exchange Membranes for Fuel Cells, Macromolecules, 2010, 43(15), 6398-6405, DOI: 10.1021/ma1010099.

38 M. Dang, Q. Deng, G. Fang, D. Zhang, J. Liu and S. Wang, Preparation of Novel Anionic Polymeric Ionic Liquid Materials and Their Potential Application to Protein Adsorption, J. Mater. Chem. B, 2017, 5(31), 6339-6347, DOI: 10.1039/C7TB01234A.

39 A. Y. Bilibin, T. M. Shcherbinina, N. V. Girbasova, V. T. Lebedev, Y. V. Kulvelis, V. S. Molchanov and I. M. Zorin, Colloidal Properties of Polymerizable Counterion Surfmers Solutions Based on Alkylamino 2-Acrylamido-2-Methylpropanesulfonates in Different Solvents, Des. Monomers Polym., 2016, 19(5), 369-380, DOI: 10.1080/15685551.2016.1169371.

40 L. W. Fisher, A. R. Sochor and J. S. Tan, Chain Characteristics of Poly(2-Acrylamido-2Methylpropanesulfonate) Polymers. 1. Light-Scattering and Intrinsic-Viscosity Studies, Macromolecules, 1977, 10(5), 949-954, DOI: 10.1021/ma60059a012.

41 L. W. Fisher, A. R. Sochor and J. S. Tan, Chain Characteristics of Poly(2-Acrylamido-2-Methylpropanesulfonate) 
Polymers. 2. Comparison of Unperturbed Dimensions and Persistence Lengths, Macromolecules, 1977, 10(5), 955-959, DOI: 10.1021/ma60059a013.

42 R. L. Weber, Y. Ye, A. L. Schmitt, S. M. Banik, Y. A. Elabd and M. K. Mahanthappa, Effect of Nanoscale Morphology on the Conductivity of Polymerized Ionic Liquid Block Copolymers, Macromolecules, 2011, 44(14), 5727-5735, DOI: 10.1021/ma201067h.

43 Y. Gu and T. P. Lodge, Synthesis and Gas Separation Performance of Triblock Copolymer Ion Gels with a Polymerized Ionic Liquid Mid-Block, Macromolecules, 2011, 44(7), 1732-1736, DOI: 10.1021/ma2001838.

44 P. Coupillaud, M. Fèvre, A.-L. Wirotius, K. Aissou, G. Fleury, A. Debuigne, C. Detrembleur, D. Mecerreyes, J. Vignolle and D. Taton, Precision Synthesis of Poly(Ionic Liquid)-Based Block Copolymers by Cobalt-Mediated Radical Polymerization and Preliminary Study of Their SelfAssembling Properties, Macromol. Rapid Commun., 2014, 35(4), 422-430, DOI: 10.1002/marc.201300776.

45 K. O. Sebakhy, S. Kessel and M. J. Monteiro, Nanoreactors to Synthesize Well-Defined Polymer Nanoparticles: Decoupling Particle Size from Molecular Weight, Macromolecules, 2010, 43(23), 9598-9600, DOI: 10.1021/ ma1019889.

46 M. Siauw, B. S. Hawkett and S. Perrier, RAFT Polymerization: A Powerful Tool for the Synthesis and Study of Oligomers, in Progress in Controlled Radical Polymerization: Materials and Applications, ACS Symposium Series, American Chemical Society, 2012, vol. 1101, pp. 13-25. DOI: 10.1021/bk-2012-1101.ch002.

47 M. Wojdyr, Fityk: A General-Purpose Peak Fitting Program, J. Appl. Crystallogr., 2010, 43(5-1), 1126-1128, DOI: 10.1107/S0021889810030499.

48 X. Pan, F. Zhang, B. Choi, Y. Luo, X. Guo, A. Feng and S. H. Thang, Effect of Solvents on the RAFT Polymerization of $\mathrm{N}$-(2-Hydroxypropyl) Methacrylamide, Eur. Polym. J., 2019, 115, 166-172, DOI: 10.1016/j. eurpolymj.2019.03.016.
49 A. Goto and T. Fukuda, Kinetics of Living Radical Polymerization, Prog. Polym. Sci., 2004, 29(4), 329-385, DOI: 10.1016/j.progpolymsci.2004.01.002.

50 P. Vana, T. P. Davis and C. Barner-Kowollik, Kinetic Analysis of Reversible Addition Fragmentation Chain Transfer (RAFT) Polymerizations: Conditions for Inhibition, Retardation, and Optimum Living Polymerization, Macromol. Theory Simul., 2002, 11(8), 823835, DOI: 10.1002/1521-3919(20021101)11:8<823:: AID-MATS823>3.0.CO;2-R.

51 J. Spěváček, ${ }^{1} \mathrm{H}$ NMR Study of Styrene-Butadiene Block Copolymer Micelles in Selective Solvents, Makromol. Chem., Rapid Commun., 1982, 3(10), 697-703, DOI: 10.1002/ marc.1982.030031009.

52 K. Philipps, T. Junkers and J. Michels, The Block Copolymer Shuffle in Size Exclusion Chromatography: The Intrinsic Problem with Using Elugrams to Determine Chain Extension Success, Polym. Chem., 2021, 12, 25222531, DOI: 10.1039/D1PY00210D.

53 H. Matsuoka, M. Matsutani, E. Mouri and K. Matsumoto, Polymer Micelle Formation without Gibbs Monolayer Formation: Synthesis and Characteristic Behavior of an Amphiphilic Diblock Copolymer Having Strong Acid Groups, Macromolecules, 2003, 36(14), 5321-5330, DOI: 10.1021/ma0215161.

54 H. Matsuoka, S. Maeda, P. Kaewsaiha and K. Matsumoto, Micellization of Non-Surface-Active Diblock Copolymers in Water. Special Characteristics of Poly(Styrene)- Block -Poly (Styrenesulfonate), Langmuir, 2004, 20(18), 7412-7421, DOI: 10.1021/la0492153.

55 S. Garnier and A. Laschewsky, New Amphiphilic Diblock Copolymers: Surfactant Properties and Solubilization in Their Micelles, Langmuir, 2006, 22(9), 4044-4053, DOI: 10.1021/la0600595.

56 H. Matsuoka, H. Chen and K. Matsumoto, Molecular Weight Dependence of Non-Surface Activity for Ionic Amphiphilic Diblock Copolymers, Soft Matter, 2012, 8(35), 9140-9146, DOI: 10.1039/c2sm25710f. 